\title{
Erratum to: Relative Importance of Nutrient Load and Wind on Regulating Interannual Summer Hypoxia in the Chesapeake Bay
}

Ping Wang • Harry Wang • Lewis Linker

Published online: 5 September 2014

(C) Coastal and Estuarine Research Federation 2014

Erratum to: Estuaries and Coasts

DOI 10.1007/s12237-014-9867-5

The corrected Fig. 6 is as follows:

The online version of the original article can be found at http://dx.doi.org/ 10.1007/s12237-014-9867-5.

P. Wang $(\bowtie) \cdot H$. Wang

Virginia Institute of Marine Science, PO Box 1346, Gloucester,

VA 23062, USA

e-mail: pwang@chesapeakebay.net

L. Linker

USEPA Chesapeake Bay Program Office, 410 Severn Avenue,

Annapolis, MD 21403, USA 

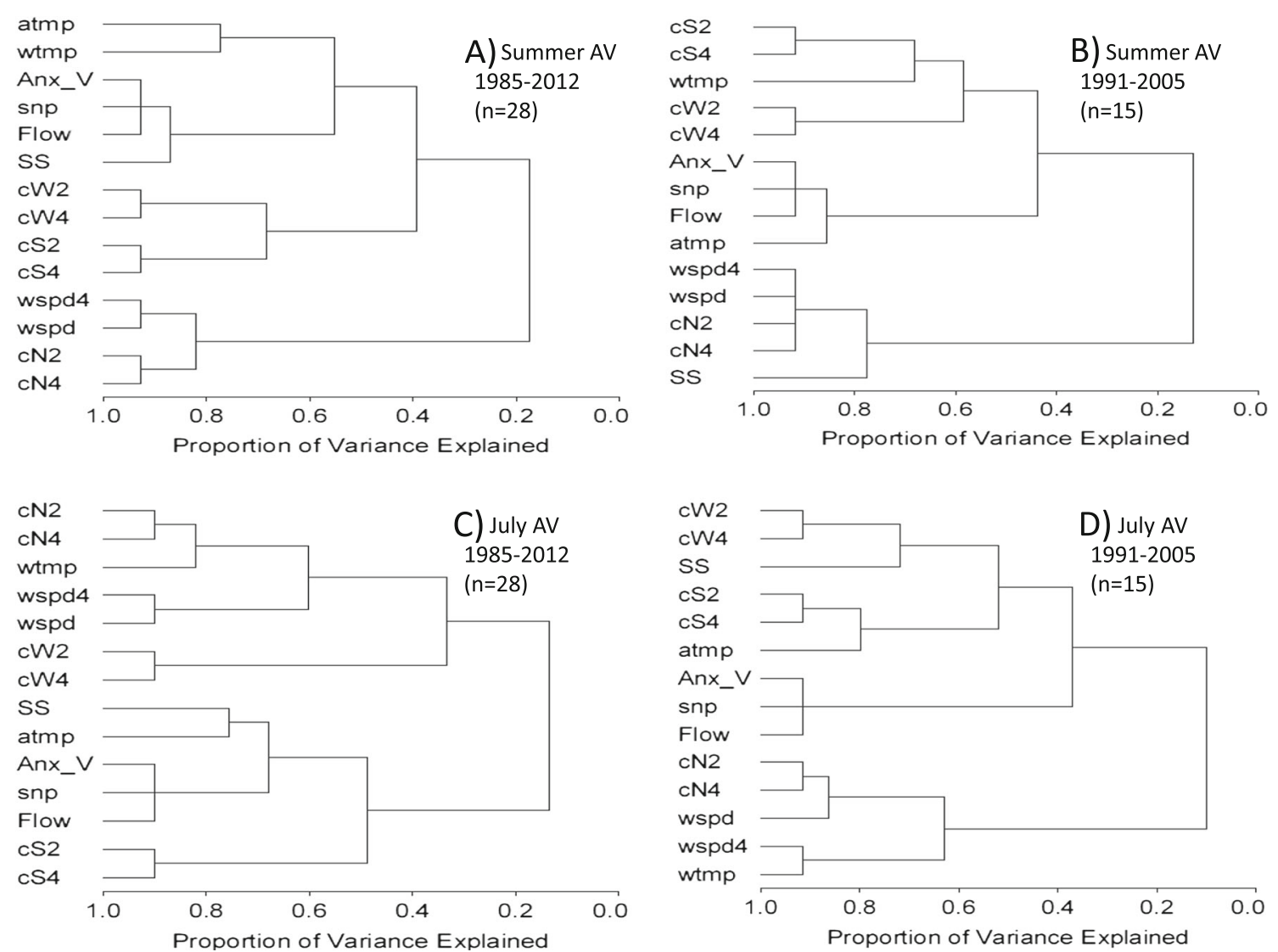

Fig. 6 Tree diagrams for anoxic volume and its influencing variables. a For summer anoxic volume, using 1985-2012 data $(n=28)$, b for summer anoxic volume, using 1991-2005 data $(n=15)$, c for July anoxic volume,

using 1985-2012 data $(n=28)$, and $\mathbf{d}$ for July anoxic volume, using $1991-2005$ data $(n=15)$ 